\title{
The Importance of an Endoscopic Quality Assessment Program Reflecting Real Practice
}

\author{
In Kyung Yoo and Yoon Tae Jeen \\ Division of Gastroenterology and Hepatology, Department of Internal Medicine, Institute of Digestive Disease and Nutrition, Korea University \\ College of Medicine, Seoul, Korea
}

See "Feedback Survey of the Effect, Burden, and Cost of the National Endoscopic Quality Assessment Program during the Past 5 Years in Korea" by Yu Kyung Cho, Jeong Seop Moon, Dong Su Han, et al., on page 542-547.

What do quality assessments have to do with practicing gastroenterologist? Why should one spend time and effort to incorporate endoscopic quality activities? First, quality improvement (QI) should directly benefit patients by ensuring they receive the highest quality of care possible. Recently, increasing the quality of endoscopy has become an important priority in Korea. Many quality indicators for gastrointestinal endoscopy have been published. ${ }^{1-4}$ Korean endoscopic quality standards were initially developed after a broad systematic review of other endoscopic quality guidelines and discussions with experts. The National Cancer Center and National Health Insurance Service (NHIS) organized the National Endoscopy QI Program in cooperation with the Korean Society of Gastrointestinal Endoscopy (KSGE). ${ }^{5}$ Quality standards have improved in the past 5 years, supported by the KSGE and NHIS.

There has been great effort to improve endoscopic quality in other countries. In England, the Bowel Cancer Screening Programme (BCSP) was introduced in 2006, targeting a moderate risk population. ${ }^{6}$ The program is based on a biennial

Received: September 12, 2016 Revised: October 28, 2016

Accepted: October 31, 2016

Correspondence: Yoon Tae Jeen

Division of Gastroenterology and Hepatology, Department of Internal Medicine, Institute of Digestive Disease and Nutrition, Korea University Anam Hospital, 73 Inchon-ro, Seongbuk-gu, Seoul 02841, Korea

Tel: +82-2-920-6555, Fax: +82-2-953-1943, E-mail: ytjeen@korea.ac.kr

cc This is an Open Access article distributed under the terms of the Creative Commons Attribution Non-Commercial License (http://creativecommons.org/ licenses/by-nc/3.0) which permits unrestricted non-commercial use, distribution, and reproduction in any medium, provided the original work is properly cited. guaiac fecal occult blood test, and if the results are positive, patients are urged to undergo a colonoscopy after a 45-minute counseling session in a specialist nurse practitioner-led clinic. Additionally, all procedures are observed, timed, and centrally reported by an independent BCSP nurse practitioner. Emerging data show that colonoscopy within the BCSP is achieving exceptionally high quality assessment (QA) standards.

In this issue of Clinical Endoscopy, Cho et al. ${ }^{7}$ report on the effects of the National Endoscopic QA Program on endoscopic practice and perceptions, burden on institutions, and costs of QA activities, especially from the viewpoint of medical institutions that conduct endoscopic screenings. A total of 67 institutions replied to the feedback survey of the National Endoscopic QA Program. They reported whether the QA program raised awareness for endoscopic quality (93\%) or improved endoscopic practice (40\%). Acceptable quality standards (45\%) and incentives/reimbursement (38\%) were considered important to the success of the QI program. In the survey, $52 \%$ of responders were conscious of considerable burdens and/or high costs while they prepared the endoscopic QA audit.

While this study offered some promising results, it also revealed several issues that we must consider.

First is the perception that QI was significantly enhanced at $93 \%$ of the medical institutions after the QA program was initiated. Approximately $80 \%$ of responders answered that all aspects of endoscopic quality had improved, including the qualifications of endoscopists, endoscopic unit facilities and equipment, endoscopic procedures and outcomes, and repro- 
cessing, which means that the quality program benefits endoscopists. Therefore, it is important to identify the necessity of a QA program and make an effort to reflect real practice.

Second, education and perceptions regarding reprocessing are important. Endoscopic reprocessing is associated with patient safety. The national QA program emphasizes strict adherence to endoscopic reprocessing guidelines. Endoscopy facilities should provide continued training and competency assessments for all staff in all areas of their activities, including clinical policies, patient monitoring, administration of intravenous medications, endoscope handling and maintenance, use of accessories, emergency procedures, decontamination, patient recovery, communication skills, and new technologies. The KSGE survey showed that the quality of endoscopic reprocessing has improved compared with results from the survey conducted 5 years prior. According to previous studies, specialized training or supervised endoscopy, use of mucolytics, appropriate use of sedation, longer inspection, extensive photo documentation, and multiple biopsies to reduce sampling error reduces overall miss rate. ${ }^{8-12}$ Periodic surveillance and practitioner education in reprocessing should be continued.

Third, in the survey, several responders felt that QI was associated with some degree of burden (48\%), especially financial burden caused by purchasing new equipment such as an endoscope or endoscopic monitoring system. Some primary clinics and private organizations that perform screening endoscopy still use low-quality or outdated endoscopic equipment. Replacing those inadequate endoscopic systems is important for proper endoscopic inspection. Financial issues generate real clinical practice problems such as reuse of disposable accessories, transport of contaminated endoscopes in a sealed container, and lack of protective eyewear. The medical cost of a screening esophagogastroduodenoscopy in Korea was approximately $1 / 14$ of the medical cost in the United Kingdom. Furthermore, medical cost did not cover any cost for disinfection. Without financial support, it is impossible to improve QA in real practice.

Fourth, our survey results may suggest that reimbursement is considered important to the success of the QI program. Cha et al. ${ }^{13}$ reported that insufficient reimbursement could be a barrier to accommodating increased endoscopic demand in the future. Furthermore, insufficient reimbursement may lead to low quality endoscopy. To accommodate an increased endoscopic demand, responders said that physicians would have to increase their working hours, which is similar to the results from the U.S. survey. ${ }^{14}$ Therefore, further studies on optimizing reimbursement for screening endoscopy in Korea are warranted. However, penalties may also be warranted for physicians who are not actively involved in data collection and measurement to improve the quality and value of their own work.

The QA program identified a clear need for high-quality clinical and outcomes research to support QI in the delivery of endoscopy services. A continuous and well-organized national endoscopic QI program is required. The new paradigm of QI seeks to improve all performance and does not simply focus on low outliers as in traditional "quality assurance" programs. Organization and key elements are emphasized, including selection of key indicators and methodologies for the development of standards of practice and benchmarks. Examples of QI initiatives are discussed, demonstrating their value for improved patient care and the process or function of an endoscopy unit. To improve the endoscopy quality program, the KSGE should try to reflect real clinical practice. Reasonable quality standards that reflect our situation and improving the insurance system are important to the success of the QA program.

Conflicts of Interest

The authors have no financial conflicts of interest.

\section{REFERENCES}

1. Armstrong D, Barkun A, Bridges R, et al. Canadian Association of Gastroenterology consensus guidelines on safety and quality indicators in endoscopy. Can J Gastroenterol 2012;26:17-31.

2. Park WG, Shaheen NJ, Cohen J, et al. Quality indicators for EGD. Am J Gastroenterol 2015;110:60-71.

3. Rizk MK, Sawhney MS, Cohen J, et al. Quality indicators common to all GI endoscopic procedures. Gastrointest Endosc 2015;81:3-16.

4. Rutter MD, Senore C, Bisschops R, et al. The European Society of Gastrointestinal Endoscopy Quality Improvement Initiative: developing performance measures. United European Gastroenterol J 2016;4:30-41.

5. Cha JM. [Quality improvement of gastrointestinal endoscopy in Korea: past, present, and future]. Korean J Gastroenterol 2014;64:320-332.

6. Sarkar S, Athwal V, Sturgess RP, Lythgoe D, Bodger K. The effect of high quality assurance measures in bowel cancer screening on patient satisfaction of colonoscopy. J Gastrointestin Liver Dis 2012;21:251-258.

7. Cho YK, Moon JS, Han DS, et al. Feedback Survey of the Effect, Burden, and Cost of the National Endoscopic Quality Assessment Program during the Past 5 Years in Korea. Clin Endosc 2016;49:542-547.

8. Gupta N, Gaddam S, Wani SB, Bansal A, Rastogi A, Sharma P. Longer inspection time is associated with increased detection of high-grade dysplasia and esophageal adenocarcinoma in Barrett's esophagus. Gastrointest Endosc 2012;76:531-538.

9. Kuo $\mathrm{CH}$, Sheu BS, Kao AW, Wu CH, Chuang $\mathrm{CH}$. A defoaming agent should be used with pronase premedication to improve visibility in upper gastrointestinal endoscopy. Endoscopy 2002;34:531-534.

10. Lal N, Bhasin DK, Malik AK, Gupta NM, Singh K, Mehta SK. Optimal number of biopsy specimens in the diagnosis of carcinoma of the oesophagus. Gut 1992;33:724-726.

11. Teh JL, Tan JR, Lau LJ, et al. Longer examination time improves detection of gastric cancer during diagnostic upper gastrointestinal endoscopy. Clin Gastroenterol Hepatol 2015;13:480-487.e2.

12. Uedo N. Do we need multiple biopsies for assessing gastric cancer risk? Dig Dis Sci 2011;56:926-928.

13. Cha JM, Moon JS, Chung IK, et al. National Endoscopy Quality 
Yoo IK et al. Endoscopic Quality Assessment Program

Improvement Program Remains Suboptimal in Korea. Gut Liver 2016;10:699-705.

14. Seeff LC, Richards TB, Shapiro JA, et al. How many endoscopies are performed for colorectal cancer screening? Results from CDC's survey of endoscopic capacity. Gastroenterology 2004;127:1670-1677. 